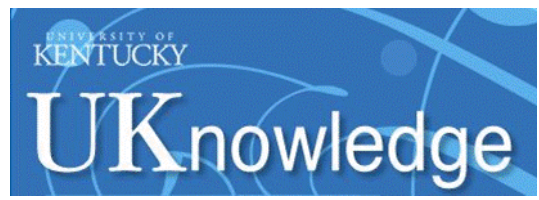

University of Kentucky

UKnowledge

Biosystems and Agricultural Engineering Faculty Publications

2016

\title{
Monitoring Yogurt Culture Fermentation and Predicting Fermentation Endpoint with Fluorescence Spectroscopy
}

Timothey P. Mains

University of Kentucky, tim.mains@uky.edu

Frederick Alan Payne

University of Kentucky, fred.payne@uky.edu

Michael P. Sama

University of Kentucky, michael.sama@uky.edu

Follow this and additional works at: https://uknowledge.uky.edu/bae_facpub

Part of the Bioresource and Agricultural Engineering Commons, Dairy Science Commons, and the Food Science Commons

Right click to open a feedback form in a new tab to let us know how this document benefits you.

\section{Repository Citation}

Mains, Timothey P.; Payne, Frederick Alan; and Sama, Michael P., "Monitoring Yogurt Culture Fermentation and Predicting Fermentation Endpoint with Fluorescence Spectroscopy" (2016). Biosystems and Agricultural Engineering Faculty Publications. 138.

https://uknowledge.uky.edu/bae_facpub/138

This Article is brought to you for free and open access by the Biosystems and Agricultural Engineering at UKnowledge. It has been accepted for inclusion in Biosystems and Agricultural Engineering Faculty Publications by an authorized administrator of UKnowledge. For more information, please contact UKnowledge@lsv.uky.edu. 


\section{Monitoring Yogurt Culture Fermentation and Predicting Fermentation Endpoint with Fluorescence Spectroscopy}

\section{Digital Object Identifier (DOI)}

https://doi.org/10.13031/trans.10838

\section{Notes/Citation Information}

Published in Transactions of the ASABE, v. 59, issue 6, p. 529-536.

(C) 2016 American Society of Agricultural and Biological Engineers

The copyright holder has granted the permission for posting the article here. 


\title{
MONITORING YOGURT CULTURE FERMENTATION AND PREDICTING FERMENTATION ENDPOINT WITH FLUORESCENCE SPECTROSCOPY
}

\author{
T. P. Mains, F. A. Payne, M. P. Sama
}

\begin{abstract}
Determination of the endpoint of yogurt culture fermentation is a process parameter that could benefit from automation. The feasibility of using a fluorescence sensor technology based on $280 \mathrm{~nm}$ excitation and $350 \mathrm{~nm}$ emission to predict the endpoint of yogurt culture fermentation was investigated and compared with the endpoint prediction from a near-infrared $(880 \mathrm{~nm})$ light backscatter sensor. Yogurt cultures with three levels of milk solids $(8 \%, 10 \%$, and $12 \%)$ and three temperatures $\left(40^{\circ} \mathrm{C}, 43^{\circ} \mathrm{C}\right.$, and $\left.46^{\circ} \mathrm{C}\right)$ were tested with three replications in a $3 \times 3$ factorial design $(n=27)$. Prediction models were developed for each optical measurement using the independent variables and time parameters calculated from the data. It was found that the fluorescence sensor technology was able to predict the endpoint of yogurt culture fermentation with a standard error of $16.0 \mathrm{~min}$ and an $R^{2}$ value of 0.999. The near-infrared sensor technology was able to predict the endpoint with a standard error of 10.4 min and an $R^{2}$ value of 0.997.
\end{abstract}

Keywords. Dairy, Fluorescence, Milk, NIR, Sensor, Spectroscopy, Tryptophan, Yogurt.

Y

ogurt is produced by the fermentation of milk by lactic acid bacteria converting lactose to lactic acid. The most common type of milk used for yogurt production is bovine milk. The casein $(\alpha \mathrm{S} 1-, \alpha \mathrm{S} 2-, \beta-$, and $\kappa$-casein) proteins in milk are responsible for the gel matrix of coagulated milk products. Skim milk is most commonly used for the fermentations and is usually fortified with lactose and milk solids to adjust the fat, sugar, and protein levels to the desired levels. During yogurt fermentation, lactic acid bacteria convert lactose into lactic acid, thereby lowering the $\mathrm{pH}$ of the milk. With the lowering of $\mathrm{pH}$, colloidal calcium phosphate is dissolved and casein is released. Three major regions are identified during the lowering of $\mathrm{pH}$ (Lucey, 2004). The first region is when the milk $\mathrm{pH}$ is reduced from 6.7 to 6.0. During this $\mathrm{pH}$ reduction, the net negative charge on the casein micelles decreases, and the electrostatic repulsion is reduced. The structural changes of the micelles are limited because only a small amount of colloidal calcium phosphate is dissolved with a $\mathrm{pH}$ above 6.0. The second region is when the milk $\mathrm{pH}$ is reduced from 6.0 to 5.0. This further decrease in $\mathrm{pH}$ decreases the net negative charge on the casein micelles, so the electrostatic repulsion and steric stabilization of the micelles also decreases. By the time the $\mathrm{pH}$ has reached 5.0, the colloidal calcium phosphate has completely dissolved. The last region is when the milk

Submitted for review in July 2014 as manuscript number PRS 10838; approved for publication by the Processing Systems Community of ASABE in September 2016.

The authors are Timothy P. Mains, Graduate Student, Fred A. Payne, ASABE Fellow, Professor Emeritus, and Michael Sama, ASABE Member, Assistant Professor, Department of Biosystems and Agricultural Engineering, University of Kentucky, Lexington, Kentucky. Corresponding author: Timothy P. Mains, 128 C.E. Barnhart Building, Lexington, KY 40506; phone: 859-421-7998; e-mail: tpmain2@uky.edu.
$\mathrm{pH}$ is reduced below 5.0. As the $\mathrm{pH}$ decreases toward the isoelectric point of the casein $(\mathrm{pH} \mathrm{4.6)}$, the net negative charge and electrostatic repulsion decrease, causing the casein micelles to aggregate and form the gel structure of yogurt.

The endpoint of the yogurt fermentation process is usually defined as the point when the $\mathrm{pH}$ of the yogurt reaches 4.6, which is when all the casein has solubilized and the gel of the yogurt has formed. Commercially, the $\mathrm{pH}$ is measured discontinuously by taking samples from the fermentation vat. Continuous $\mathrm{pH}$ measurement is not used because of the drift of $\mathrm{pH}$ probes and deposits of particulates on the probe (De Brabandere and De Baerdemaeker, 1999; Verdru, 2012, unpublished results). Other methods have been attempted to measure the progression of yogurt fermentation, including near-infrared spectroscopy (Verdru, 2012, unpublished results), near-infrared spectroscopy coupled with electronic nose (Navrátil et al., 2004), ultrasonic spectroscopy and forward-scattering diffusing wave spectroscopy (Dalgleish et al., 2003), transmission diffusing wave spectroscopy (Alexander and Dalgleish, 2004), confocal scanning laser microscopy (Hassan et al., 1995), turbidity (Banon and Hardy, 1991), mid-infrared spectroscopy and synchronous fluorescence spectroscopy (Boubellouta et al., 2011), and fluorescence spectroscopy (Herbert et al., 1999).

An automated method for determining the endpoint of yogurt fermentation is needed to improve product consistency and reduce production costs, processing time and materials used, labor costs, and work-related stress for the required labor (Bresnahan, 1997). The current practice is to initiate cooling of the yogurt when the $\mathrm{pH}$ of the yogurt reaches the target of 4.6. The $\mathrm{pH}$ is determined by sampling the fermentation vat and measuring the $\mathrm{pH}$ with a laboratory $\mathrm{pH}$ meter. This method is time consuming, as sampling and $\mathrm{pH}$ meas- 
urement may take over $5 \mathrm{~min}$ to conduct. Operators are generally responsible for multiple vats, and thus the precision of determining the $\mathrm{pH}$ of the endpoint is more related to the time availability of the operator than the accuracy of the $\mathrm{pH}$ meter.

Research has been conducted on the use of fluorescence spectroscopy to measure other dairy products and processes. Fluorescence spectroscopy has been used for a number of other analyses in the dairy industry; a review and compilation on the subject was completed by Andersen and Mortensen (2008).

Intrinsic fluorescence in proteins results from exciting the amino acid tryptophan, which contains a benzene ring in its structure. Tryptophan has excitation and emission wavelengths of $278 \mathrm{~nm}$ and $348 \mathrm{~nm}$, respectively, and has a quantum yield near 0.13 (Damodaran, 2008; Chen, 1967). Furthermore, it should be noted that the range of emission wavelengths of the amino acids tyrosine and phenylalanine falls within the range of excitation wavelengths of tryptophan, so the fluorescence of tryptophan is aided by and masks the fluorescence of tyrosine and phenylalanine (Lakowicz, 2006).

Tryptophan is an ideal indicator of protein activity due to its sensitivity to its environment. Since tryptophan is a hydrophobic amino acid, it changes its orientation within the protein with a change in $\mathrm{pH}$ and temperature. As lactic acid bacteria convert lactose into lactic acid during yogurt culture fermentation, the environment of the milk changes, so electrostatic attraction becomes more prevalent among the casein molecules. This environmental change as the fermentation progresses promotes the reorientation of the tryptophan amino acids so that the indole portion is within the structure of the protein, thereby shielding it from external sources of light and decreasing fluorescence (Rahimi Yazdi and Corredig, 2012).

An infrared light backscatter sensor technology for monitoring milk coagulation is currently being used to predict the endpoint of the enzymatic coagulation of milk (CoAguLite Model 6, Reflectronics, Inc., Lexington, Ky.). It was proposed that a fluorescence sensor technology based on UV excitation at $280 \mathrm{~nm}$ and emission measurement at $350 \mathrm{~nm}$ could predict yogurt culture endpoint as well or better than the infrared light backscatter sensor technology.

The objective of this study was to investigate the feasibility of using a fluorescence sensor technology for predicting the endpoint of yogurt culture fermentation and to compare the endpoint prediction accuracy with that from an infrared light backscatter sensor technology over a broad range of milk solids content and fermentation temperatures. A successful technology would need to predict the fermentation endpoint with accuracy over a broad range of conditions.

\section{Materials ANd Methods Milk Preparation ANd FERmentation}

Grade A low-heat nonfat dry milk powder (O-AT-KA Milk Products Cooperative, Inc., Batavia, N.Y.) was stirred into $1000 \mathrm{~mL}$ of filtered deionized water for $3 \mathrm{~h}$ to achieve solids concentration levels of $8 \%, 10 \%$, or $12 \%$ and refrigerated overnight. The next day, prior to fermentation, the milk was pasteurized at $80^{\circ} \mathrm{C}$ for $30 \mathrm{~min}$ in a water bath. The pasteurized milk was inoculated with $0.02 \%\left(\mathrm{~g} \mathrm{~L}^{-1}\right)$ of starter culture (YF-L702, Chr. Hansen, Inc., Milwaukee, Wisc.) containing Streptococcus thermophilus and Lactobacillus delbrueckii subsp. bulgaricus. Approximately 5 min after inoculation, each testing vat was filled with $100 \mathrm{~mL}$ of inoculated milk and covered to block out ambient light and eliminate evaporation. The remaining $800 \mathrm{~mL}$ in the fermentation vessel was covered to prevent surface evaporation, and the vessel was placed in a water bath that was set to the fermentation temperature $\left(40^{\circ} \mathrm{C}, 43^{\circ} \mathrm{C}\right.$, or $\left.46^{\circ} \mathrm{C}\right)$ for the duration of the fermentation test.

\section{Testing Apparatus}

Two testing vats were temperature controlled using a circulating water bath, as shown in figure 1. Optical units for continuous fluorescence and infrared reflectance measurements were installed in the separate vats. Each optical unit included an input for a light source and an output for a detection unit. The light source and detection unit for the fluorescence testing vat were a $280 \mathrm{~nm}$ LED (model UVTOP280TO18BL, Sensor Electronic Technology, Inc., SETI, Columbia, S.C.) and a spectrophotometer (model HR4000, Ocean Optics, Dunedin, Fla.), respectively. A constant current of $25 \mathrm{~mA}$ was provided to the LED by an integrated circuit (model 4006-025, LUXDrive series, DynaOhm, Randolph, Vt.). The spectrophotometer took spectral scans in the range of 200 to $1100 \mathrm{~nm}$ with data collection controlled by SpectraSuite software (Ocean Optics, Dunedin, Fla.).

The light source and detection unit for the near-infrared reflectance testing vat were a $880 \mathrm{~nm}$ LED (model L2791-

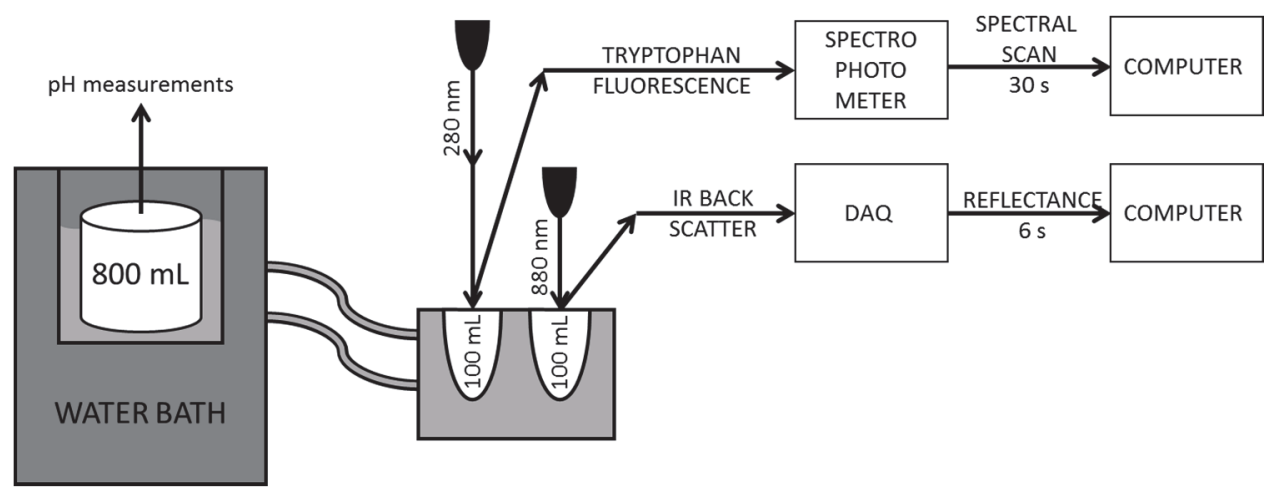

Figure 1. Diagram of testing apparatus and equipment. 
02, Hamamatsu, Bridgewater, N.J.) and photodiode (model TSL267, ams AG, Raleigh, N.C.) connected to a data acquisition (DAQ) board (model USB-1608FS, Measurement Computing Corp., Norton, Mass.), respectively. The DAQ board provided a constant $+5 \mathrm{~V}$ source for the LED and photodiode. Custom DAQ software was programmed to record the near-infrared reflectance data.

\section{SPECTRAL SCANS AND DATA PROCESSING}

Fluorescence spectral scans were taken every $30 \mathrm{~s}$. The fluorescence response measured by the spectrophotometer was extracted from the spectral scans with an Excel VBA macro. The fluorescence signal over the range of 315 to $365 \mathrm{~nm}$ was integrated, resulting in one optical intensity reading for each spectral scan.

Near-infrared reflectance was measured once per second, and the average of six readings was recorded every $6 \mathrm{~s}$. The near-infrared response was normalized by dividing by the average response during the first hour of fermentation.

The fluorescence response was normalized by dividing each data point by the average fluorescence collected during the second hour of fermentation. The fluorescence signal decreased by about $10 \%$ to $20 \%$ during the first hour of testing, resulting from what was considered photo-bleaching. The average fluorescence collected during the second hour was chosen over the first hour because of its relative stability.

A derivative analysis was conducted after normalization of the fluorescence and infrared signals. The first, second, and third derivatives were calculated. The derivative calculations for the fluorescence signal used $7 \mathrm{~min}$ of data containing 14 data points. The difference between the average of the seven leading and seven trailing data points was calculated. This difference was divided by the time difference to give the slope. For the infrared data, 42 data points were used. The time parameters characterizing the fermentation process were defined by the minima and maxima for each derivative. Each minima and maxima was labeled according to the derivative $(1,2$, or 3$)$, whether it was a minimum (MIN) or maximum (MAX), occurrence $(1,2, \ldots)$, and whether it was derived from near-infrared reflectance (IR) or fluorescence (FL).

\section{FERMENTATION pH MEASUREMENTS}

Fermentation $\mathrm{pH}$ was measured with a $\mathrm{pH}$ meter (Orion $520 \mathrm{~A}+$, Thermo Scientific, Waltham, Mass.) equipped with a pH probe (Orion 8102BN, Thermo Scientific, Waltham, Mass.). The $\mathrm{pH}$ was recorded by taking a sample from the fermentation vessel every $20 \mathrm{~min}$ from the beginning of the fermentation to $\mathrm{pH} 6.0$, every $10 \mathrm{~min}$ from $\mathrm{pH} 6.0$ to $\mathrm{pH} 5.0$, and every $20 \mathrm{~min}$ from $\mathrm{pH} 5.0$ to the end of fermentation. All tests were conducted over a period of 27 days, with one fermentation performed per day. Each fermentation required approximately $300 \mathrm{~min}$ to reach the endpoint $\mathrm{pH}$ of 4.6.

\section{EXPERIMENTAL DESIGN}

Yogurt was made from fermented milk using three solids concentrations $(8 \%, 10 \%$, and $12 \%)$ and three fermentation temperatures $\left(40^{\circ} \mathrm{C}, 43^{\circ} \mathrm{C}\right.$, and $\left.46^{\circ} \mathrm{C}\right)$ with three replications to cover a broad range of conditions typical of industrial processes. SAS (ver. 9.3, SAS Institute, Inc., Cary, N.C.) was used for all statistical analyses and model predictions. An ANOVA was performed to test the significance of the test parameters of fermentation temperature and percent milk solids content to verify that they actually affected the measured endpoint. The performance of each model was based on minimizing the coefficient of variation and standard error of prediction for the model.

\section{RESULTS AND DISCUSSION \\ CHANGES IN FLUORESCENCE, NEAR-INFRARED, AND PH RESPONSES DURING FERMENTATION}

The fluorescence signal in the wavelength range of 315 to $365 \mathrm{~nm}$ decreased over the period of fermentation (fig. 2). It was concluded that the tryptophan reoriented itself within the structure of the casein, blocking it from the excitation light, which resulted in the fluorescence signal decreasing as the fermentation progressed.

The normalized fluorescence and infrared reflectance responses and $\mathrm{pH}$ are plotted in figure 3 for a typical yogurt fermentation. Both the fluorescence and near-infrared reflectance responses were unchanged in the first region and in one-third of the second region, and both followed the three major regions proposed by Lucey (2004). The $\mathrm{pH}$ dropped

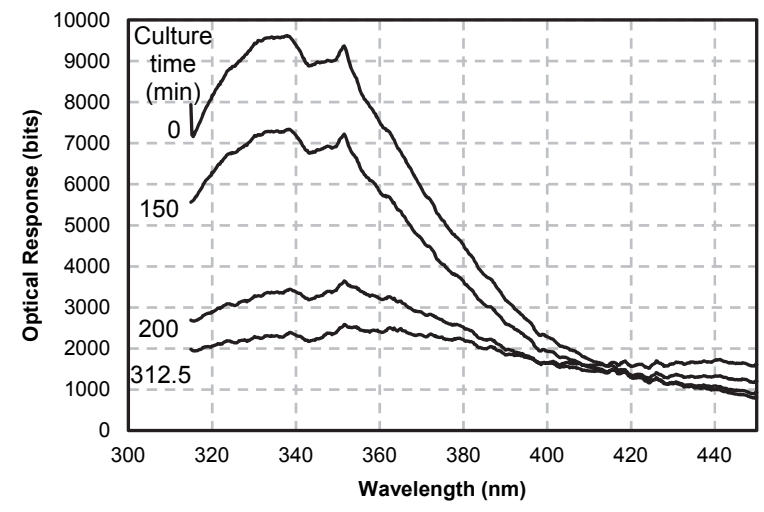

Figure 2. Fluorescence response measured with spectrophotometer during fermentation of a typical yogurt sample for culture times of 0 , 150,200 , and $312.5 \mathrm{~min}$.

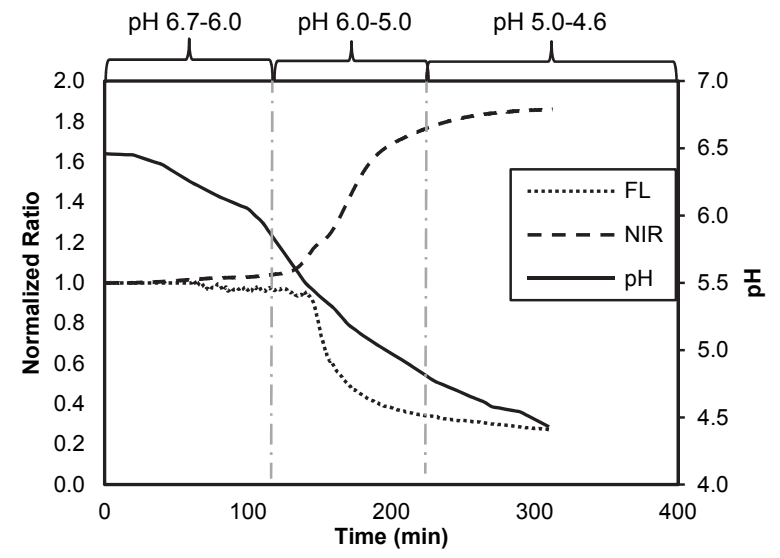

Figure 3. Normalized fluorescence (FL), normalized near-infrared reflectance (NIR), and $\mathrm{pH}$ responses during fermentation of a typical yogurt sample. 
throughout the fermentation, but the fastest drop was in the second region, when the $\mathrm{pH}$ dropped from 6.0 to 5.0. Both the fluorescence and near-infrared reflectance responses exhibited large changes in the second region and smaller changes in the third region.

The first region, from $\mathrm{pH} 6.7$ to $\mathrm{pH} 6.0$ and from 0 to $120 \mathrm{~min}$, was marked by very little change in fluorescence, as shown in figure 3. Since only a small amount of colloidal calcium phosphate was dissolved during this phase, there was very little change in the structure of the casein molecules. The second region, from $\mathrm{pH} 6.0$ to $\mathrm{pH} 5.0$ and from 120 to $180 \mathrm{~min}$, showed a rapid decrease in fluorescence. During this phase, the majority of the structural changes of the casein occurred. The drop in $\mathrm{pH}$ changed the environment of the milk and promoted electrostatic attraction between casein molecules, which caused the hydrophobic tryptophan to reorient itself. The reorientation caused the fluorescent indole region of the tryptophan to rotate about the peptide bond, going from the outside of the protein structure to the inside. As the indole reoriented itself, it was shielded from light by the outside of the casein protein structure, and therefore a decrease in fluorescence occurred (Rahimi Yazdi and Corredig, 2012). The third region, below pH 5.0 and from 180 to $\sim 300 \mathrm{~min}$, showed a slight decrease in fluorescence, which coincided with a slight increase in electrostatic attraction, causing the tryptophan to fully rotate within the casein protein structure, resulting in a reduction of fluorescence, and the final tryptophan fluorescence signal was reached.

The near-infrared light backscatter data collected during yogurt culture fermentation followed a coagulation curve typical of milk coagulation processes measured by similar near-infrared reflectance techniques (O'Callaghan et al., 2000; Payne et al., 1993). The near-infrared light backscatter profile illustrates the three regions of fermentation proposed by Lucey (2004). In the first region, there was little change in the near-infrared light backscatter because there was very little change in the structure of the casein. In the second region, the electrostatic attraction between the casein molecules rapidly increased, causing the casein molecules to become highly attracted to each other and aggregate. When this occurred, the light backscatter increased. In the third region, the electrostatic attraction between the casein molecules slightly increased as the $\mathrm{pH}$ approached the isoelectric point of the casein and the endpoint of fermentation. The near-infrared light backscatter increased slightly in this region.

The results of the ANOVA (table 1) showed that the fermentation temperature and percent milk solids content significantly affected the endpoint. However, the interaction between the two was not significant. The milk solids content was shown to have a greater influence on the endpoint, with a probability factor of 0.0072 , compared with the fermentation temperature, which had a probability factor of 0.012 .

Table 1. ANOVA of milk solids content, fermentation temperature, and their interaction.

\begin{tabular}{cccccc}
\hline & & ANOVA & Mean & F & \\
Source & df & SS & Square & Value & Pr $>$ F \\
\hline Solids & 2 & 8582 & 4291 & 6.57 & 0.0072 \\
Temp & 2 & 7489 & 3744 & 5.73 & 0.012 \\
Temp $\times$ Solids & 4 & 5196 & 1292 & 1.98 & 0.141 \\
\hline
\end{tabular}

The time of the endpoint of fermentation decreased quadratically as the fermentation temperature increased (fig. 4a). This is shown by taking the square of the fermentation temperature and fitting a linear line. The rate of reaction increased linearly with solids (fig. 4b). These trends were in agreement with the results reported by Wu et al. (2009).

The data were analyzed to determine if there was a relationship between measured fluorescence and product $\mathrm{pH}$ after the $\mathrm{pH}$ decreased below 5.0. Figure 5 shows the measured fluorescence response as a function of product $\mathrm{pH}$ for the three solids levels. The slopes of these curves (measured fluorescence change per $\mathrm{pH}$ change) varied with milk solids content $(S, \%)$ and fermentation temperature $\left(T,{ }^{\circ} \mathrm{C}\right)$ and could be calculated with a linear regression model: slope $=$ $0.002 T+0.0169 S$. This linear relationship has potential for use in processing plants to predict the processing time needed for a specific change in $\mathrm{pH}$ to occur. However, further research is needed to confirm and refine this approach for endpoint prediction.

\section{Prediction Models of FERMENTATION EndPoint}

Models for predicting the fermentation endpoint $\left(t_{\text {end }}\right)$ were developed using the independent variables of temperature and milk solids content along with time parameters. For each model, a regression procedure was run to determine which combination of input variables would provide the best model for predicting $t_{\text {end }}$ based on minimizing the coefficient of variation and the standard error of prediction.
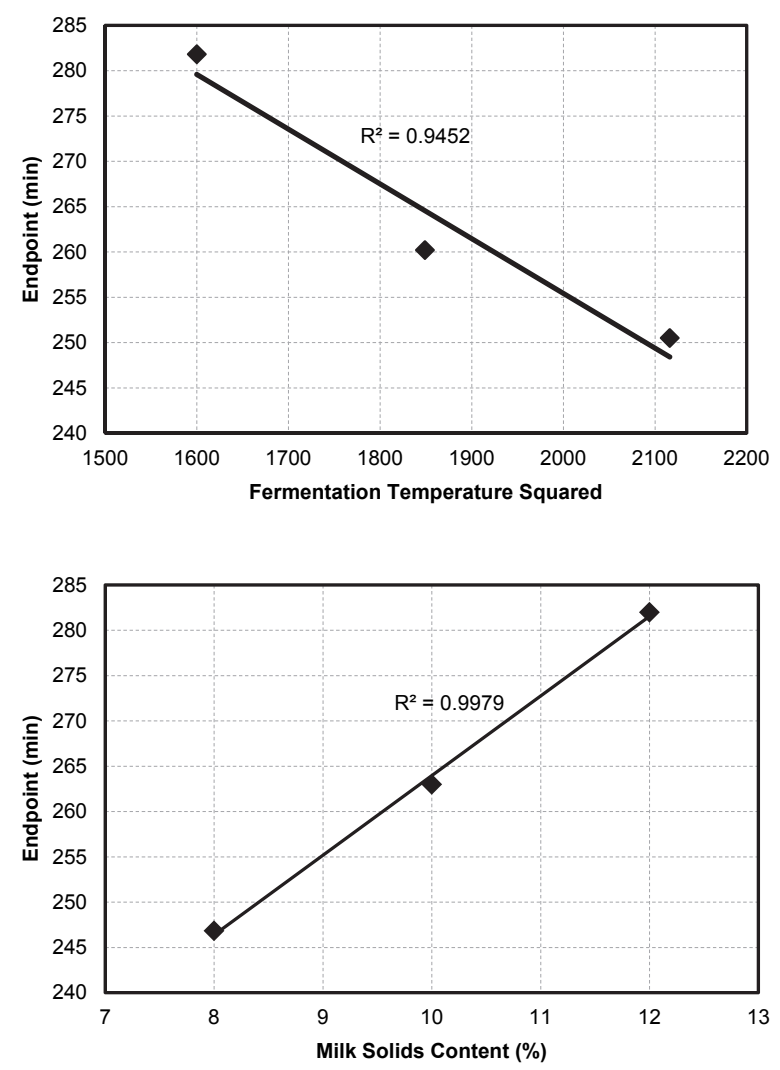

Figure 4. Average endpoint of fermentation as a function of (a) fermentation temperature squared and (b) milk solids content. 

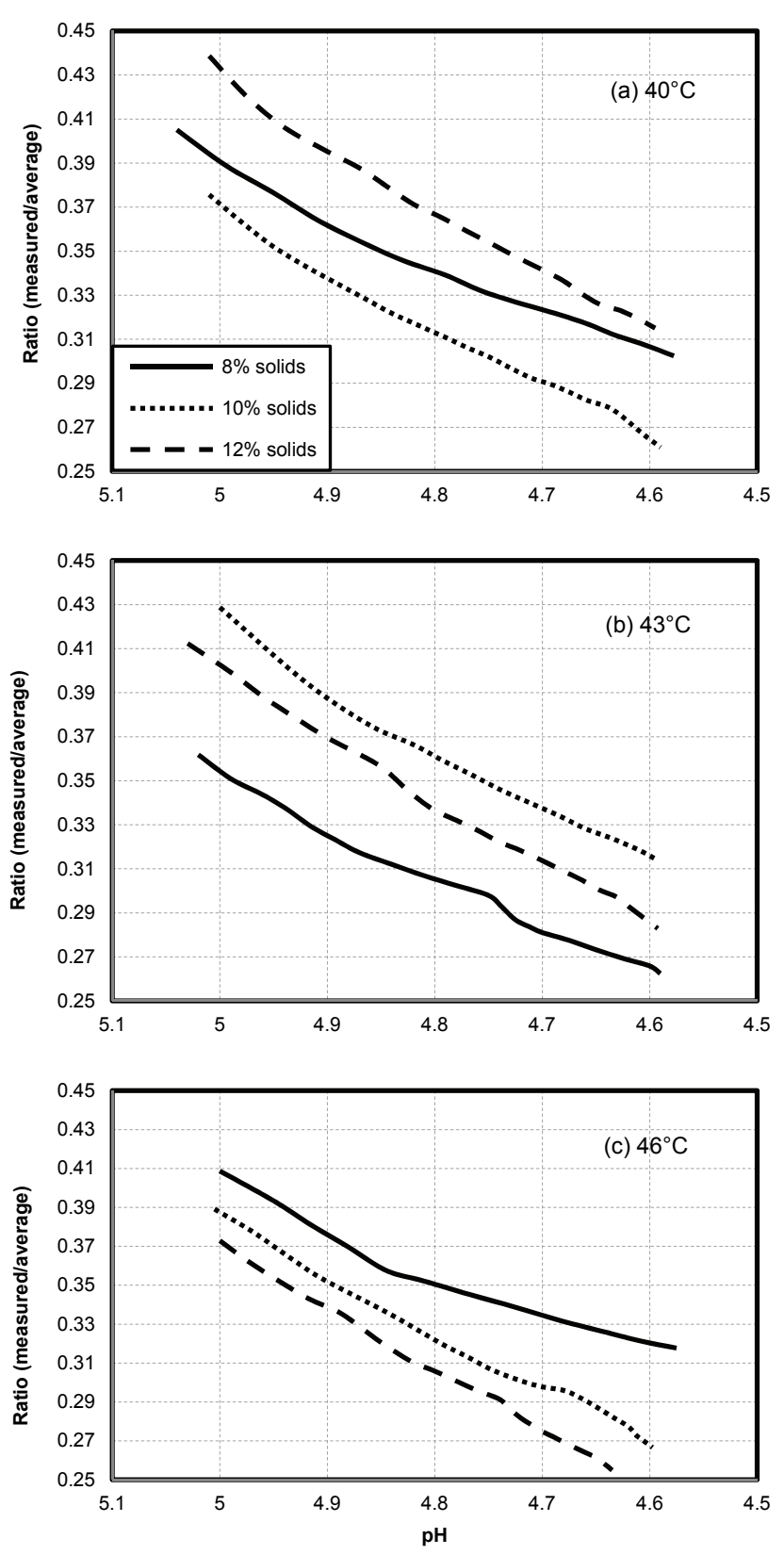

Figure 5. Change in fluorescence response for $8 \%, 10 \%$, and $12 \%$ milk solids content at (a) $40^{\circ} \mathrm{C}$, (b) $43^{\circ} \mathrm{C}$, and (c) $46^{\circ} \mathrm{C}$ from $\mathrm{pH} 5.0$ to 4.6.

\section{Model 1: Fluorescence Spectral Response}

The fluorescence time parameters and independent variables were used to determine a model for endpoint prediction. The first-derivative minimum (T1MIN1FL), second-derivative minimum (T2MIN1FL), second-derivative maximum (T2MAX1FL), and third-derivative maximum (T3MAX1FL) were the time parameters calculated from the normalized fluorescence spectra and are illustrated in figure 6a. These time parameters, milk solids content, and fermentation temperature were analyzed using the general linear model procedure (PROC GLM) in SAS to develop the following model (model 1) for predicting the endpoint of fermentation $\left(t_{\text {end }}\right)$ :

$$
\begin{aligned}
t_{\text {end }} & =\beta_{1} S+\beta_{2} T+\beta_{3}(\mathrm{~T} 1 \mathrm{MIN} 1 \mathrm{FL}) \\
& +\beta_{4}(\mathrm{~T} 2 \mathrm{MAX} 1 \mathrm{FL}-\mathrm{T} 2 \mathrm{MIN} 1 \mathrm{FL})
\end{aligned}
$$

The resulting regression coefficients were $\beta_{1}=8.41, \beta_{2}=$ $-1.41, \beta_{3}=0.755$, and $\beta_{4}=13.0$. This model had an $\mathrm{R}^{2}$ value of 0.997 , a coefficient of variance of $6.08 \%$, and a standard error of prediction of $16.02 \mathrm{~min}$ and was the best model developed in terms of minimizing the standard error of prediction.

The coefficient for milk solids content was positive as expected, showing that the endpoint increased as the solids content increased. The fermentation temperature coefficient was negative, showing that the endpoint decreased as the temperature increased, also as expected. The T1MIN1FL coefficient was positive, indicating that a delayed occurrence of this time parameter led to an increase in the endpoint. The coefficient of the difference between T2MAX1FL and T2MIN1FL was positive, indicating that the magnitude of this value can be used to judge the rate of fermentation. A larger difference would have indicated a slower fermentation and therefore an increase in the endpoint. The observed and predicted endpoints using model 1 are shown in figure $6 \mathrm{~b}$.

\section{Model 2: Near-Infrared Spectral Response}

The near-infrared time parameters and independent variables were used to determine a model for the endpoint prediction. Two first-derivative time parameter maxima (T1MAX1IR and T1MAX2IR), two second-derivative minima (T2MIN1IR and T2MIN2IR), two second-derivative maxima (T2MAX1IR and T2MAX2IR), and two third-derivative maxima (T3MAX1IR and T3MAX2IR) of the normalized near-infrared spectral response are shown in figure $6 \mathrm{c}$. The two maxima of the first derivative indicated that there were two regions when the rate of the change in light backscatter peaked. The second first-derivative maximum was greater than the first, so the rate of change of the light backscatter was at its peak at the second maximum.

These time parameters, milk solids content, and fermentation temperature were analyzed using the general linear model procedure (PROC GLM) in SAS to develop the following model for predicting the endpoint of fermentation $\left(t_{\text {end }}\right)$ :

$$
t_{\text {end }}=\beta_{1} S+\beta_{2}(\mathrm{~T} 3 \mathrm{MAX} 2 \mathrm{IR})+\beta_{3}(\mathrm{~T} 2 \mathrm{MAX} 2 \mathrm{IR})
$$

The resulting regression coefficients were $\beta_{1}=8.72, \beta_{2}=$ -27.3 , and $\beta_{3}=27.6$. The fit had an $\mathrm{R}^{2}$ value of 0.999 , a coefficient of variance $=3.96 \%$, and a standard error of prediction of $10.43 \mathrm{~min}$ (fig. $6 \mathrm{~d}$ ).

The coefficient for solids content was positive, as with model 1. Milk solids content is one of the parameters required to predict the endpoint of yogurt fermentation, as milk components can act as buffers to prevent the lowering of $\mathrm{pH}$ as lactose is converted to lactic acid by the starter culture. Hence, increasing milk solids content increases the fermentation endpoint (Wu et al., 2009). However, unlike model 1, the fermentation temperature was not included in model 2 despite the fact that it showed significance in the ANOVA. The exclusion of fermentation temperature was based on the inclusion of more additional time parameters in the model 


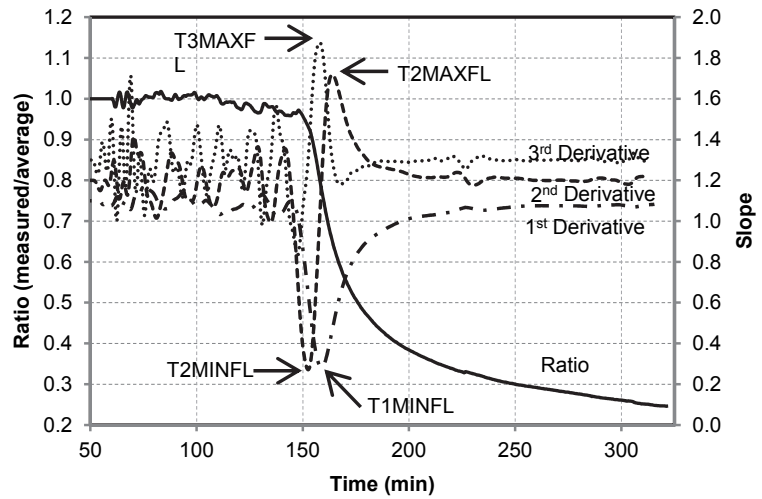

(a) Normalized fluorescence response, derivatives, and corresponding time parameters

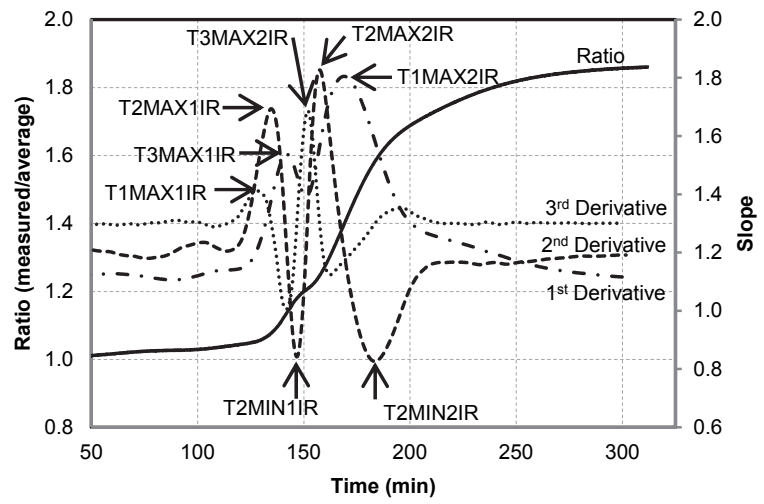

(c) Normalized near-infrared response, derivatives, and corresponding time parameters

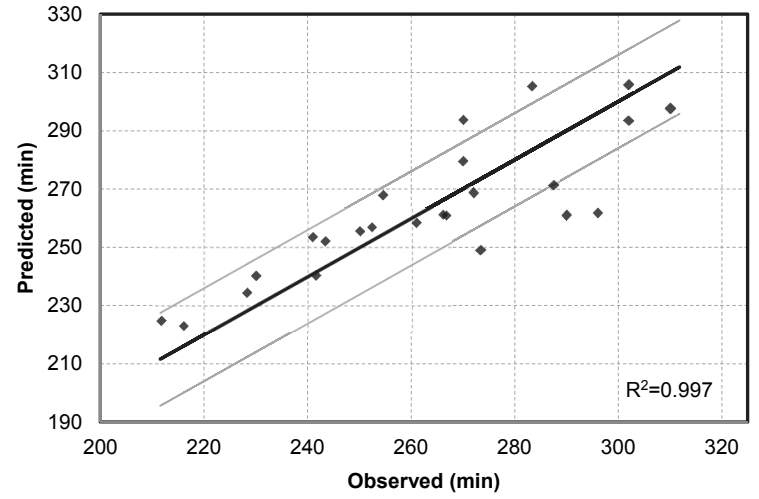

(b) Calibration results with $95 \%$ confidence intervals of model 1 (based on fluorescence response)

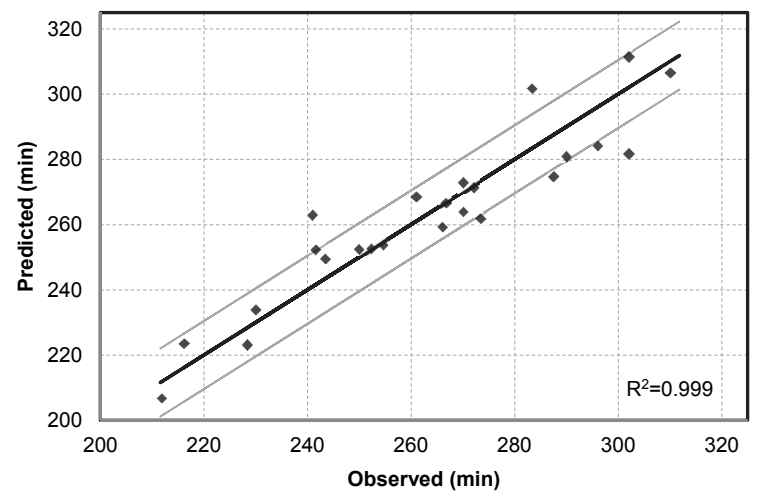

(d) Calibration results with $95 \%$ confidence intervals of model 2 (based on near-infrared response)

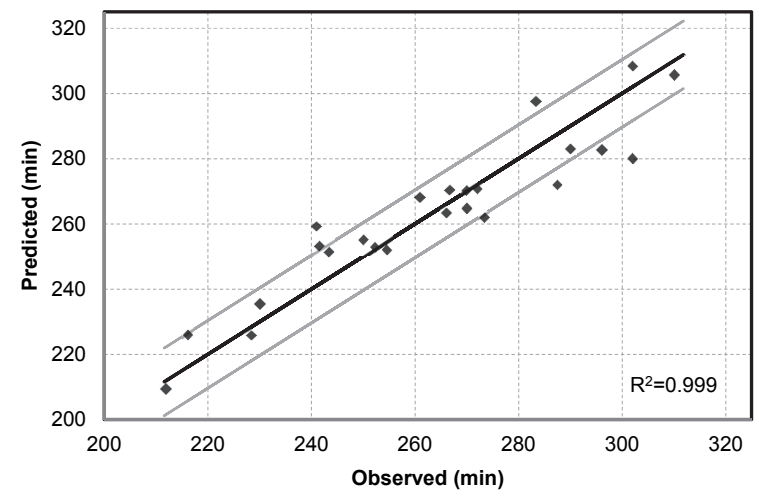

(e) Calibration results with $95 \%$ confidence intervals of model 3 (based on fluorescence and near-infrared responses)

Figure 6. Three prediction models for yogurt fermentation endpoint were developed based on milk solids content, fermentation temperature, the normalized spectral responses, their derivatives, and corresponding time parameters. Calibration results with $95 \%$ confidence intervals showed that all three models captured over $98 \%$ of the variability in the endpoint.

that could effectively account for temperature effects. The T3MAX2IR coefficient was negative, indicating that this time parameter was used to adjust the prediction of the endpoint. An earlier occurrence of this time parameter would indicate a faster fermentation, and therefore a smaller adjustment would be made; the opposite would be true for a later occurrence. The T2MAX2IR coefficient was positive, indicating that a delayed occurrence of this time parameter would lead to an increase in the endpoint.

\section{Model 3: Combined Fluorescence and Near-Infrared Spectral Responses}

A sensor technology that incorporates both an infrared and fluorescence measurements is technically feasible. The two signals may provide an improvement in endpoint prediction accuracy. Thus, a third model was developed using both the fluorescence and near-infrared spectral data to determine if a more accurate endpoint prediction model could be developed. The fluorescence and near-infrared time pa- 
rameters, milk solids content, and fermentation temperature were analyzed using the general linear model procedure (PROC GLM) in SAS to develop the following model for predicting the endpoint of fermentation $\left(t_{\text {end }}\right)$ :

$$
\begin{aligned}
t_{\text {end }} & =\beta_{1} S+\beta_{2}(\text { T3MAX2IR })+\beta_{3}(\text { T2MAX2IR }) \\
& +\beta_{4}(\text { T1MIN1FL })
\end{aligned}
$$

The resulting regression coefficients were $\beta_{1}=10.4, \beta_{2}=$ $-32.4, \beta_{3}=29.9$, and $\beta_{4}=2.57$. For this model, the $\mathrm{R}^{2}$ value was 0.999 , the coefficient of variance was $3.94 \%$, and the standard error of prediction was $10.37 \mathrm{~min}$. As with the previous models, the solids content coefficient was positive, the T3MAX2IR coefficient was once again negative, and the T2MAX2IR and T1MIN1FL coefficients were positive.

Model 3 combined the technologies of both fluorescence and near-infrared reflectance in an attempt to create a model that could predict the endpoint of yogurt fermentation better than either individual technology. The standard errors of prediction for model 1 (fluorescence), model 2 (near-infrared), and model 3 (combined) were 16.02, 10.43, and $10.37 \mathrm{~min}$, respectively. A closer look at model 3's predicted vs. observed fermentation endpoints showed that model 3 was similar to model 2 (fig. 6e), indicating that model 3's prediction accuracy was more dependent on the near-infrared reflectance time parameters than the fluorescence time parameter. Based on the regression parameter statistics for model 3 (not shown), near-infrared light backscatter had a much greater impact on the prediction of the endpoint. This was supported by the coefficients for this model, with the coefficients for the near-infrared light backscatter time parameters greater than the coefficient for the fluorescence time parameter, further indicating that near-infrared light backscatter was more influential in this model. Based on these results, the fluorescence sensor output offers no advantage over the infrared using linear regression models to predict the endpoint. There are possibilities that the linear relationship between $\mathrm{pH}$ and fluorescence could be developed with further study to generate a predictor of the endpoint. Additionally, nonlinear models may also be investigated.

\section{Conclusions}

In this study, the viability of using a fluorescence sensor technology for predicting the endpoint of yogurt culture fermentation over a range of milk solids contents and fermentation temperatures was investigated and compared to the performance of a near-infrared light backscatter sensor.

A linear relationship was found between the $\mathrm{pH}$ and fluorescence signal after the $\mathrm{pH}$ decreased below 5.0. The slope of the line varied with fermentation temperature and milk solids content. Overall, the average fermentation endpoint decreased quadratically as the fermentation temperature increased and increased linearly as the milk solids content increased.

Linear models were developed using the time parameters generated from the fluorescence and near-infrared response with the independent variables solids and temperature. Three linear models were developed for endpoint prediction: model 1 (fluorescence), model 2 (near-infrared), and model 3 (combined fluorescence and infrared), with resulting standard errors of predictions of 16.02, 10.43, and $10.37 \mathrm{~min}$, respectively. Although the linear models did not show that the fluorescence sensor had an advantage over the infrared sensor, advantages may be developed by exploring the linear relationship between $\mathrm{pH}$ and fluorescence as fermentation approaches the endpoint.

\section{ACKNOWLEDGEMENTS}

Thanks to the University of Kentucky for providing the resources and facilities for research.

\section{REFERENCES}

Alexander, M., \& Dalgleish, D. G. (2004). Application of transmission diffusing wave spectroscopy to the study of gelation of milk by acidification and rennet. Colloids Surf. B, 38(1-2), 83-90. http://dx.doi.org/10.1016/j.colsurfb.2004.08.012

Andersen, C. M., \& Mortensen, G. (2008). Fluorescence spectroscopy: A rapid tool for analyzing dairy products. J. Agric. Food. Chem., 56(3), 720-729. http://dx.doi.org/10.1021/jf072025o

Banon, S., \& Hardy, J. (1991). Study of acid milk coagulation by an optical method using light reflection. J. Dairy Res., 58(1), 75-84. http://dx.doi.org/10.1017/S0022029900033525

Boubellouta, T., Galtier, V., \& Dufour, E. (2011). Structural changes of milk components during acid-induced coagulation kinetics as studied by synchronous fluorescence and midinfrared spectroscopy. Appl. Spectrosc., 65(3), 284-292. http://dx.doi.org/10.1366/10-05907

Bresnahan, D. (1997). Chapter 16: Process control. In Handbook of food engineering practice. Boca Raton, FL: CRC Press. http://dx.doi.org/10.1201/9781420049077.ch16

Chen, R. F. (1967). Fluorescence quantum yields of tryptophan and tyrosine. Anal. Lett., 1(1), 35-42. http://dx.doi.org/10.1080/00032716708051097

Dalgleish, D., Alexander, M., \& Corredig, M. (2004). Studies of the acid gelation of milk using ultrasonic spectroscopy and diffusing wave spectroscopy. Food Hydrocolloids, 18(5), 747-755. http://dx.doi.org/10.1016/j.foodhyd.2003.12.001

Damodaran, S. (2008). Amino acids, peptides, and proteins. In Fennema's food chemistry (pp. 217-329). Boca Raton, FL: CRC Press.

De Brabandere, A. G., \& De Baerdemaeker, J. G. (1999). Effects of process conditions on the $\mathrm{pH}$ development during yogurt fermentation. J. Food Eng., 41(3-4), 221-227. http://dx.doi.org/10.1016/S0260-8774(99)00096-5

Hassan, A. N., Frank, J. F., Farmer, M. A., Schmidt, K. A., \& Shalabi, S. I. (1995). Formation of yogurt microstructure and three-dimensional visualization as determined by confocal scanning laser microscopy. J. Dairy Sci., 78(12), 2629-2636. http://dx.doi.org/10.3168/jds.S0022-0302(95)76892-8

Herbert, S., Riaublanc, A., Bouchet, B., Gallant, D. J., \& Dufour, E. (1999). Fluorescence spectroscopy investigation of acid- or rennet-induced coagulation of milk. J. Dairy Sci., 82(10), 20562062. http://dx.doi.org/10.3168/jds.S0022-0302(99)75446-9

Lakowicz, J. (2006). Principles of fluorescent spectroscopy. New York, NY: Springer Science + Business Media. http://dx.doi.org/10.1007/978-0-387-46312-4

Lucey, J. A. (2004). Formation, structural properties, and rheology of acid-coagulated milk gels. In Cheese: Chemistry, physics, and microbiology (pp. 105-122). Cambridge, MA: Academic Press. http://dx.doi.org/10.1016/S1874-558X(04)80064-2 
Navratil, M., Cimander, C., \& Mandenius, C.-F. (2004). On-line multisensor monitoring of yogurt and filmjölk fermentations on production scale. J. Agric. Food. Chem., 52(3), 415-420. http://dx.doi.org/10.1021/jf0304876

O'Callaghan, D. J., O'Donnell, C. P., \& Payne, F. A. (2000). Online sensing techniques for coagulum setting in renneted milks. J. Food Eng., 43(3), 155-165. http://dx.doi.org/10.1016/S02608774(99)00145-4

Payne, F. A., Hicks, C. L., Madangopal, S., \& Shearer, S. A. (1993). Fiber optic sensor for predicting the cutting time of coagulating milk for cheese production. Trans. ASAE, 36(3), 841-847. http://dx.doi.org/10.13031/2013.28407

Rahimi Yazdi, S., \& Corredig, M. (2012). Heating of milk alters the binding of curcumin to casein micelles: A fluorescence spectroscopy study. Food Chem., 132(3), 1143-1149. http://dx.doi.org/10.1016/j.foodchem.2011.11.019

Wu, S., Li, D., Li, S., Bhandari, B., Yang, B., Chen Xiao, D., \& Mao, Z. (2009). Effects of incubation temperature, starter culture levels, and total solids content on the rheological properties of yogurt. Intl. J. Food Eng., 5(2). 10.2202/1556-3758.1436 